\title{
CHANGE IN GROWTH AND YIELD CHARACTERISTICS OF MUSA CV MYSORE ("EMBUL" BANANA) WITH INCREASING AGE OF THE CROP
}

\section{J.A. SIRISENA ${ }^{1}$ and S.G.J.N. SENANAYAKE ${ }^{2}$}

1 Regional Agricultural Research and Development Centre, Department of Agriculture, Angunakolapelessa.

2 Department of Agricultural Biology, Faculty of Agriculture, University of Ruhuna, Mapalana, Kamburupitiya.

(Received: 05 September 1996; accepted: 04 July 1997)

\begin{abstract}
Banana (Musa spp.) is a major semi-perennial fruit crop in Sri Lanka. A study was conducted at the Regional Agricultural Research and Development Centre, Angunakolapelessa to investigate the effect of age on growth and yield of banana cv Mysore ("Embul", AAB group). Thirty-seven "Embul" banana accessions collected from various ecological regions of Sri Lanka were studied in a Randomized Complete Block Design with three replicates. The observations were recorded in three consecutive years. Number of leaves per clump, LAI (leaf area index) and penetration of photosynthetically active radiation (PAR) to the crop were recorded at 4, 9, 20 and 32 months after planting. Pseudostem height and girth of the crop were investigated at different ages. Number of combs and fruits per comb, fruit maturity period, bunch weight, total fruit weight, average fruit weight and peduncle weight were also measured. Comb weight, fruit circumference, fruit length and diameter were recorded in the second and last combs. Leaf number and LAI increased, while penetration of PAR decreased with the age. Except weight of second comb, fruit length in second comb and fruit diameter in last comb, all other characteristics varied significantly with age of the crop. Fruit maturity period increased with the age of the crop to second year and then decreased, while total fruit weight decreased up to second year and then increased. Number of fruits per comb and bunch weight significantly increased after the second year. Stem height and girth, number of fruits per bunch, weight of the peduncle and length of the male axis consistently increased with the age of the crop investigated up to the third year.
\end{abstract}

Key words: Banana, Musa spp., yield.

\section{INTRODUCTION}

Banana (Musa spp.) is a major semi-perennial fruit crop in Sri Lanka. There are about 27-28 cultivars grown in the country. ${ }^{1}$ National annual production of $731,000 \mathrm{~m}$.tons was recorded from an estimated 44,578 ha of banana cultivated throughout the country. ${ }^{2}$ Cultivar Mysore ("Embul", AAB group) is most popular, yields well, has good keeping qualities, and can be cultivated in most agro-ecological zones. The life-span of banana crop mainly depends upon the level of crop management. Some growers in Sri Lanka harvest only the first bunch of the crop and no suckers are allowed to grow for subsequent crops. 
However, majority of the growers in Sri Lanka maintain their crop for many years depending upon management conditions. The gross yields of banana has been found highest in the plant crop and decreased in ratoon crops to a constant level. ${ }^{1}$ Thirty-five percent yield reduction in first ratoon over the plant crop was observed in "Dwarf Cavendish" banana in French Guinea. ${ }^{1,3}$ It is not possible to maintain a crop for long periods, if the harvest price is dependant on the grade of the fruits since this declines with the age of the crop. ${ }^{1}$ However, the effect of the crop's age on the yield and quality of banana has not been experimentally assessed and causes for such effects have also not been identified. There are no reports available on the yield parameters affected by the age of the crop in local cvs of Sri Lanka. Therefore, the main objective of the present study was to carry out investigations on the effect of crop's age on yield parameters of "Mysore" banana in Sri Lanka.

\section{METHODS AND MATERIALS}

Crop Management: The experiment was conducted at the Regional Agricultural Research and Development Centre, Angunakolapelssa, Sri Lanka (1200 mm average annual total rainfall and 30 m elevation) during the period 1992 to 1995. Thirty-seven accessions of Musa cv Mysore with diverse morphological characters were selected and multiplied in the field using naturally emerging suckers. The accessions collected were grown in a Randomized Complete Block Design with three replicates. Sword suckers with the height of $1.5-2.0 \mathrm{~m}$, uniform in size and age were used as planting materials. Blades of broad leaves of suckers and all the dead portions of the rhizomes were removed. The rhizomes were treated with fungicide "Dithane" mixed with dry wood-ash. Treated suckers were kept under shade for about $24 \mathrm{~h}$ before planting. The suckers were planted in July 1992 in planting holes $(45 \mathrm{~cm} \times 45 \mathrm{~cm} \mathrm{x} 45 \mathrm{~cm}$ ) with distance of $3 \mathrm{~m}$ both within and between rows. Each planting hole was filled with well decomposed cow-dung mixed with top soil. $600 \mathrm{~g}$ of dolomite were applied to each planting hole as recommended by the Department of Agriculture, Sri Lanka, as calcium and magnesium source. Banana cultivar Seenikesel (Pisang awak) plants were established around the experimental area to avoid border effects and wind damages. $15 \mathrm{~g}$ of carbofuran ( $3 \% \mathrm{G}$.) was applied to each planting hole at the time of planting to control banana nematode Radopholus similis. Irrigation was done once in ten days satisfying the field capacity of the soil depth at $75 \mathrm{~cm}$ when dry climatic condition prevailed more than $10 \mathrm{~d}$. Fertilizer mixture 12: 8: 34: (N:P:K) recommended by the Department of Agriculture was applied at the rate of $450 \mathrm{~g}$ per clump, two months after planting. This was repeated at four months intervals. Fertilizer was applied, $45 \mathrm{~cm}$ radius around the clump at $3-5 \mathrm{~cm}$ depth of the soil. First daughter sucker was allowed to emerge at four months of planting and the second at flowering of the plant crop (8-9 months). The third one was allowed to emerge at the time when the bunch matured (10-12 months). Subsequently, one additional sucker was allowed to emerge whenever the 
mother plant was removed from the clump because of harvesting the bunch. Therefore the clump consisted of one plant until 4 months of planting, two plants from 4-9 months and three plants at 12 months onwards. Thereafter, three plants in a clump with an age difference of 3-4 months were maintained.

Growth Characters: The time of planting, time of flowering and fruit maturity in each plant of the clump were recorded with the growth of the crop. The number of leaves per clump was recorded at 4, 9, 20 and 32 months of planting of the crop. The number of plants available for leaf measurements was one at four months, two at nine months, three at the end of the first year and thereafter. The leaf area was calculated from the length of leaf blade using the method described previously. ${ }^{1,4}$ Therefore, leaf blade lengths were recorded in their order of insertion to estimate leaf area in each individual leaf. The total leaf area was estimated for the clump and then for each block of banana separately. The total leaf area in each block was divided by block area to compute leaf area index (LAI). The leaf-blade length was measured from distal end to base of the leaf blade at 4, 9, 20 and 32 months of planting, with a light wooden stick calibrated in $\mathrm{cm}$. The pseudostem height from ground level to base of the leaf petioles and the pseudostem girth at $10 \mathrm{~cm}$ above ground level were measured, at the time of bunch harvesting.

Fruit Measurements: Harvesting was done at the time when one fruit of the first or second comb turned green to yellow. Bunches with male axis and male bud were cut at $60 \mathrm{~cm}$ of peduncle before the first comb. After harvesting, combs were counted and removed from peduncle and tagged to identify their sequence in the bunch. Fruit clusters consisting of more than four filled fruits were considered as combs. The weight of the second comb and the last comb in each bunch was also recorded. The total fruit weight was taken by weighing the combs. The bunch weight was measured excluding male axis and male bud. Number of fruits per bunch was also counted. The weight of the peduncle was measured including the male axis. Fruit circumference was measured at the middle of the fruit by wrapping a measuring tape around it. The fruit diameter was measured in the cross section taken at the middle of the fruit. This measurement was taken in three different directions of the cross section of the fruit using a Vernier calliper and the mean value was calculated. Fruit length was measured after removing fruit stalk and the bottle-neck part in distal end of the fruit. All the fruit measurements were taken for three fruits in a comb. Fruit measurements were taken in second and last combs in each bunch. All the growth and fruit measurements were taken for the fruit bunches harvested during 1993 to 1995 and average value for each replicate was presented for the statistical analyses. Data were analysed using the $\mathrm{F}$ test at significance range of $0.1-5 \%$. 
Physiological Measurements: The daily measurements of sunshine hours were taken during the experimental period from the Meteorological Unit, Regional Agricultural Research and Development Centre, Angunakolapelessa and presented as daily mean per month (Table 1). These measurements were taken on sunshine scales (Casella, London) with the recorder model M/8068 (Negretti, Zambra, London). Photosynthetically active radiation (PAR) was also measured at 4,9,20 and 32 months after planting in conjunction with LAI measurements taken.

Table 1: Mean sunshine hours at Regional Agricultural Research and Development Centre during the experimental period from 1992-1995.

\begin{tabular}{lcccc}
\hline Month & \multicolumn{4}{c}{ Average daily sunshine hours } \\
\cline { 2 - 5 } & 1992 & 1993 & 1994 & 1995 \\
\hline January & - & 8.5 & 6.0 & 6.0 \\
February & - & 8.8 & 7.8 & 7.8 \\
March & - & 9.1 & 8.1 & 8.1 \\
April & - & 6.8 & 7.5 & 7.5 \\
May & - & 5.4 & 8.0 & 8.2 \\
June & - & 7.7 & 6.1 & 6.1 \\
July & 6.5 & 9.0 & 8.0 & 8.0 \\
August & 7.0 & 7.5 & 7.6 & 6.5 \\
September & 7.6 & 7.6 & 6.5 & 5.0 \\
October & 7.5 & 5.5 & 5.4 & 7.0 \\
November & 4.4 & 5.6 & 5.0 & 7.0 \\
December & 4.2 & 4.5 & 7.2 & 6.5 \\
\hline
\end{tabular}

- = experiment was planted in July 1992.

PAR was measured with a PAR meter model SKP-200 (Sky Instruments, Llandriolod Wells, UK). Measurements were taken at the bases of the plants, towards five cardinal points from 0900 to $1500 \mathrm{~h}$ at $3 \mathrm{~h}$ intervals for one week and averaged for daily variation for different age of the crop mentioned (Table. 2). 
Table 2: Daily mean variation of light penetration to banana crop at different ages in comparison to direct light penetration.

\begin{tabular}{|c|c|c|c|}
\hline Age of the crop & Time & $\begin{array}{l}\text { Penetration of } \\
\text { photosynthetically } \\
\text { active radiation } \\
(\mathrm{PAR}), \mu \mathrm{mol} . \mathrm{sm}^{-2} . \mathrm{s}^{-1}\end{array}$ & $\begin{array}{c}\text { Daily } \\
\text { mean of } \\
\text { PAR } \\
\left(\mu \mathrm{mol} . \mathrm{sm}^{-2} \cdot \mathrm{s}^{-1}\right)\end{array}$ \\
\hline \multirow[t]{3}{*}{4} & $0900 \mathrm{~h}$ & 866 & 1069 \\
\hline & $1200 \mathrm{~h}$ & 1706 & \\
\hline & $1500 \mathrm{~h}$ & 566 & \\
\hline \multirow[t]{3}{*}{9} & $0900 \mathrm{~h}$ & 107 & 767 \\
\hline & $1200 \mathrm{~h}$ & 1684 & \\
\hline & $1500 \mathrm{~h}$ & 512 & \\
\hline \multirow[t]{3}{*}{20} & $0900 \mathrm{~h}$ & 84 & 591 \\
\hline & $1200 \mathrm{~h}$ & 1470 & \\
\hline & $1500 \mathrm{~h}$ & 221 & \\
\hline \multirow[t]{3}{*}{32} & $0900 \mathrm{~h}$ & 71 & 503 \\
\hline & $1200 \mathrm{~h}$ & 1370 & \\
\hline & $1500 \mathrm{~h}$ & 70 & \\
\hline Above crop & $0900 \mathrm{~h}$ & 1179 & 1484 \\
\hline canopy & $1200 \mathrm{~h}$ & 1982 & \\
\hline (control) $)^{*}$ & $1500 \mathrm{~h}$ & 1291 & \\
\hline
\end{tabular}

$=$ mean value of the four measurements (taken on sunny days)

\section{RESULTS}

Average number of leaves per clump increased as $4 \pm 0.5,12 \pm 1,18 \pm 1.5$ and $18 \pm 2$ during the measurements taken at $4,9,20$ and 32 months of age respectively. Similarly, the LAI of the crop also increased as $0.61 \pm 0.11,3 \pm 0.21$, $4.2 \pm 0.28$ and $4.5 \pm 0.34$ measured at $4,9,20$ and 32 months of age respectively. The light penetration to the crop measured as PAR was reduced from 1046 to 503 $\mu \mathrm{mol} \cdot \mathrm{m}^{-2} \cdot \mathrm{s}^{-1}$ (mean measurement from $0900-1500 \mathrm{~h}$ ) during the period from 4 to 32 months of age (Table 2).

The growth and yield parameters that were significantly different between different ages of the crop and the level of significance are indicated in Table 3. 
Table 3: Level of Statistical Significance in different Characters.

Character

F value ( $220 \mathrm{df}$ )

and significant level

Pseudostem height

$264.23^{* * *}$

Pseudostem girth

$107.43^{\text {*** }}$

Bunch maturity period

$5.62^{* * *}$

Bunch weight

$6.92^{* *}$

Total fruit weight

$6.35^{* *}$

Number of combs per bunch

$41.04^{* * * *}$

Number of fruits per bunch

$51.18^{* * * *}$

Average no. of fruits per comb

$6.6^{* *}$

Average fruit weight

$23.78^{* * *}$

Weight of last comb

$18.31^{* * *}$

Fruit length in last comb

$11.67^{* * *}$

Fruit diameter in second comb

$6.21^{* *}$

Weight of peduncle

$14.13^{* *}$

Male axis length

$22.77^{* * *}$

Weight of second comb

$0.51 \mathrm{~ns}$

Fruit length in second comb

$2.10 \mathrm{~ns}$

Fruit circumference in last comb

$1.75 \mathrm{~ns}$

Fruit diameter in last comb

$2.12 \mathrm{~ns}$

${ }^{* *}=$ significant at $1 \%$ level, ${ }^{\cdots *}=$ significant at $0.1 \%$ level

$\mathrm{ns}=$ not significant

The pseudostem height, pseudostem girth, number of fruits per bunch and length of male axis increased significantly $(p<0.001)$ from first year to third year of age (Table 4). Similarly, number of combs per bunch and weight of peduncle increased significantly $(\mathrm{p}<0.001)$ during this period (Table 4$)$. The average fruit weight of the bunch and fruit length of the last comb decreased significantly $(p<0.001$ ) with the age of the crop (Table 4). The fruit length in the second comb, weight of the second comb, fruit diameter and fruit circumference in last comb did not vary significantly $(p>0.05)$ with the age. The fruit maturity period was significantly $(p<0.01)$ increased in second and third year over the first year, but there was no significant difference $(p>0.05)$ between second and third year (Table 4). Bunch weight, total fruit weight and number of fruits per comb were not significantly increased $(p>0.05)$ up to the second year, but there was a significant increase in these characters $(p<0.01)$ during the third year (Table 4). 
Table 4: Variation of growth and fruit characteristes in Musa cv Mysore ("Embul" banana) at different ages of the crop.

\begin{tabular}{|c|c|c|c|c|}
\hline \multirow[t]{2}{*}{ Growth/Fruit } & \multicolumn{3}{|c|}{ Variation at different ages } & \multirow[t]{2}{*}{ S.E.D $(220 \mathrm{df})^{: "}$} \\
\hline & Year 1 & Year 2 & Year 3 & \\
\hline Pseudostem height $(\mathrm{cm})$ & 248 & 312 & 350 & 2.8 \\
\hline Pseudostem girth $(\mathrm{cm})$ & 59 & 67 & 72 & 0.5 \\
\hline F. maturity period (days) & 102 & 104.7 & 104 & 0.45 \\
\hline Bunch wt.(kg) & 12.3 & 12.3 & 13.5 & 0.21 \\
\hline Total fruit wt. (kg) & 10.5 & 10.3 & 11.4 & 0.18 \\
\hline No. of combs per bunch & 10.6 & 11.7 & 12.1 & 0.01 \\
\hline No. of fruits per bunch & 158 & 176 & 196 & 2.2 \\
\hline Av. no. of F. per comb & 15 & 15 & 16.4 & 0.43 \\
\hline Av. wt. of the fruit (g) & 66 & 59 & 55.5 & 0.9 \\
\hline $\begin{array}{l}\text { F. diameter in second } \\
\text { comb }(\mathrm{cm})\end{array}$ & 3.46 & 3.55 & 3.20 & 0.06 \\
\hline Wt. of last comb (g) & 389 & 262 & 263 & 13.9 \\
\hline F. length in last comb $(\mathrm{cm})$ & 8.9 & 8.5 & 8.1 & 0.09 \\
\hline Wt. of peduncle $(\mathrm{kg})$ & 1.8 & 2.0 & 2.2 & 0.037 \\
\hline Male axis length $(\mathrm{cm})$ & 157 & 166 & 174 & 1.40 \\
\hline
\end{tabular}

* $=$ Standard error difference at 220 degrees of freedom.

The fruit diameter in second comb did not significantly vary $(p>0.05)$ from first year to second year but a significant decrease $(p<0.01)$ was observed in the third year (Table 4). The weight of the last comb increased significantly $(p<0.001)$ from first year to second year but no significant difference $(p>0.05)$ was observed in this character between second and third year (Table 4). 


\section{DISCUSSION}

It was revealed that plant height and girth increased from first year to third year in this experiment. A positive correlation between pseudostem height and the girth has been previously reported for "Dwarf Cavendish" banana in Queensland, ${ }^{5}$ Musa AAB group in Africa $^{6}$ and East African highland bananas. ${ }^{7}$ Therefore, it is evident that positive correlation between pseudostem height and the girth in cv Mysore evaluated in this study exists. The pseudostem height has also been increased when plant density increased in "Cavendish" banana (AAA group) in India ${ }^{8}$ and in the second and third cycles of "William" (AAA group) banana in Africa. ${ }^{9}$ Similarly, in this experiment plant density increased during the first year because of the increase in plant number in the clump. Therefore, increase in pseudostem height in ratoon crops in this experiment may be due to increase in plant density resulting from increased clump size. Light penetration in the form of PAR was reduced with increasing age of the crop to a maximum of $50 \%$ measured from 4 months to 32 months of age in this experiment. Seventy percent reduction of light penetration was reported with the increasing canopy for "William" banana in third cycle grown with the density of $1000 \mathrm{clumps} / \mathrm{ha}$ in Africa. ${ }^{9}$ Therefore, the elongation of pseudostem height in ratoon crop of this experiment could be due to reduced light penetration resulting from increased foliage.

LAI increased in ratoons with increasing age of the crop up to a maximum of 4.5. LAI also increased up to 6.3 in "William" banana in the third cycle grown at the density of 2222 clumps/ha in Africa. ${ }^{9}$ Further, the leaf area has also been positively correlated with pseudostem height of "Cavendish" banana in Ivory Coast. ${ }^{10}$ The peduncle weight and the male axis length also increased with the age of the crop in this study probably be due to increased leaf area and leaf number.

Bunch weight, total fruit weight and number of fruits per comb increased in the third year over the first and second year. The number of fruits per bunch and the number of combs per bunch progressively increased from the first year to the third year of the crop. Higher yield has been correlated with higher number of leaves, greater LAI, greater pseudostem height and girth in highland bananas in Uganda. ${ }^{7}$ However, bunch yield has been better correlated with pseudostem girth than the pseudostem height in Musa $\mathrm{AAB} \mathrm{cv}$ Agbagba in Nigeria. ${ }^{11}$ The bunch yield has also been correlated with the leaf number in the first and second cycles of the crop in a mulching experiment in South Nigeria. ${ }^{12}$ In contrast, there were some reports on the reduction of gross yield in ratoons of "Gross Michel" (AAA group) banana in commercial fields. ${ }^{1,3}$ However, these authors have not assessed the yield related vegetative characters or yield components. Therefore, increase in fruit yield, fruit number, comb number, fruit weight and comb weight in ratoon crops in this study could be due to increase in LAI in ratoon crops over 
the plant crop. Increase in yield related vegetative characters such as pseudostem height and girth in ratoon crop strongly support the yield increase in this experiment from year one to three.

The average fruit weight, fruit circumference and fruit length in the last comb decreased from year one to three in this study. Fruit weight has been negatively correlated with density of the plants in "Cavendish" banana. ${ }^{8}$ Poor light penetration into increased foliage in ratoon crops may be the reason for poor grade of the fruits in ratoon crops investigated up to three years in this experiment.

\section{Acknowledgements}

This research was supported by The Council for Agricultural Research Policy. Authors thank Professor Rohan Rajapakse, University of Ruhuna, for valuable suggestions.

\section{References}

1. Simmonds N.W. (1966). Bananas. 2nd ed. pp. 190-194. Tropical Agriculture Series, Longman, London.

2. Mannion H.J., Martin F.W. \& Duncun A.A. (1992). Horticultural assessment commodity and program recommendations. Report on Diversified Agricultural Research Project. pp 9-10. Department of Agriculture, Sri Lanka.

3. Anon (1952). Quelques reflexions sur la culture de bananier. In: Bananas (Ed. N.W. Simmonds) 2nd ed. pp. 20-42. Longman, London.

4. Skutch A.F. (1927). Anatomy of leaf of banana, Musa sapientum L. var. Hort. Gros Michel. Botanical Gazette 84: 337-391.

5. Summerville W.A.T. (1944). Studies in nutrition as qualified by development in Musa Cavendishii Lambert. Queensland Journal of Agricultural Science 1: 1-127.

6. Swennen R., Vuylsteke D. \& Ortiz R. (1995). Phenotipic diversity and patterns of variation in West and Central African plantains (Musa spp.; $\mathrm{AAB}$ group). Economic Botany 49(3): 320-327.

7. Mukumbi D. \& Rubaihayo P.R. (1994). Evaluation of Uganda highland banana germplasm. African Crop Science Society, Kampala 1: 183-187. 
8. Chattopadhyay P.K., Chattopadhyay S., Maiti S.C. \& Bose T.K. (1980). Effect of plant density on growth, yield and quality of banana. In: Proceedings of the National Seminar on Banana. Production Technology (Eds. C.R. Muthukrishnen \& J.B.M.M. Abdul Khader) pp 85-88. Tamilnadu Agricultural University, Coimbatore, India.

9. Robinson J.C. \& Nel D.J. (1985). The influence of banana plant density on ratoon cycle interval. In: Proceedings of the Fifteenth Annual Congress. South African Society of Crop Production 15:178-185.

10. Alexandrowicz L. (1955). Etude du development de l'inflorescence du bananier nain. In: Bananas (Ed. N.W.Simmonds) 2nd ed. pp. 36-37. Longman, London.

11. Baiyeni K.P. \& Mbah B.N (1994). Growth and yield correlation in false horn plantain (Musa AAB “Agbagba”) in a sub-humid zone of Nigeria. Musafirica 10(5): 3-4.

12. Salan O.A., Opera Nadi O.A. \& Swennen R. (1992). Effect of mulching on soil properties, growth and yield of plantain on a tropical ultisol in Southeastern Nigeria. Soil and Tillage Research 23: 73-93. 